\author{
Professor Ioan RADU, PhD \\ E-mail: iradu13@gmail.com \\ Professor Ion SMEUREANU, PhD \\ E-mail: smeurean@ ase.ro \\ Professor Minodora URSĂCESCU, PhD \\ E-mail: minodora.ursacescu@ man.ase.ro \\ Associate professor Cleopatra ȘENDROIU, PhD \\ E-mail: cleosendroiu@gmail.com \\ Mihai Ludovic DEMETER, PhD Candidate \\ E-mail: mihaidemeter2004@gmail.com \\ Cristian ANTON, PhD Candidate \\ E-mail: Tony_cristi2004@yahoo.com \\ The Bucharest University of Economic Studies
}

\title{
A NEW SIMULATION MODEL FOR HEATING PRODUCTION PLANS: A CASE STUDY ON ROMANIAN DISTRICT HEATING SYSTEMS
}

\begin{abstract}
Improved efficiency in district heating systems is an important topic for citizens and industrial consumers, especially in the context of environmental issues and increased energy efficiency. The purpose of this research is to determine the optimal quantity of heat energy that should be produced by thermal power plants to be delivered to the population during the cold season. To that end, a simulation model is proposed in order to meet a certain level of demand, but also to satisfy an optimum economic level. The model includes two optimization methods: The first is a linear optimization model, in which different production plans are optimized to achieve various economic optimum criteria. The second method, based on an algorithm derived from fuzzy theory, considers all previous production plans that were obtained, in order to determine the optimal decisions in a multi-criteria context. The simulation model was applied to eight Romanian power plants which produce heat between October and March to satisfy the thermal requirements of the housing sector. The findings reveal that the simulation model could provide an interactive decision support system that can be used to plan the amount of heat to be produced according to economic, social, and environmental priorities.
\end{abstract}

Keywords: district heating, energy efficiency, simulation models, production plans, housing sector.

JEL Classification: C61, D24, L23, M11 
Ioan Radu, Ion Smeureanu, Minodora Ursăcescu, Cleopatra Șendroiu, Mihai Demeter, Cristian Anton

\section{Introduction}

District heating $(\mathrm{DH})$ is a system for distributing heat, generated from one or more sources, by a network of insulated pipes carrying steam or hot water to heated buildings (Martin \& Thornley P,, 2013). The sustainability of the service is assured by its lower heating costs, even when international fuel prices are high, leading to economic, social, and environmental benefits (Chittum \& Østergaard, n.d.); (Colemnar-Santos, et al., 2016); (Galindo Fernández, et al., 2016); (Leca, 2015).

District heating is the most efficient hot water and heat insurance system for citizens and industrial consumers. The fundamental idea of district heating is to use local fuel or heat resources that would otherwise be wasted in order to satisfy local customer demands for heating (Werner, 2004). In this respect, the main benefit of DH is its heating costs, which are low in the context of international fuel prices. Compared to individual household heating devices, the DH system has the advantage of producing heat efficiently (often also electricity, through cogeneration) at a lower price. At the same time, DH can use many types of fuel (e.g., coal or fuel oil), which allows it to function even when the provision of natural gas is interrupted.

Another important issue of DH is related to environmental protection. Despite its inherent technical and infrastructural rigidities, the district heating system has a lower negative impact on the environment, compared to other heating systems, as the power plants are usually situated in the peripheral areas of the city. One of the environmental benefits of district heating is the higher air quality resulting from large combustion plants, which replace many small local boilers (Gasparini et al., 2015). In fact, for individual consumers, DH is a safe system with no risk of explosion or asphyxiation when compared to a home heating system that might be inappropriately installed or checked.

Related to the environmental context, district heating systems should be aligned to the national legislation and the European regulations. The primary issue of such systems refers to the need to reduce their generation of carbon dioxide emissions. From this perspective, DH companies should consider how they could decarbonize their heat networks in order to diminish their environmental impact. According to the European directives, the DH network is forced to align with EU regulations referring to greenhouse gas $(\mathrm{GHG})$ emissions from heating (EC (European Commission), 2009) (EC (European Commision), 2012).

The many different applications of district heating make it a useful system. The current DH systems provide space heating and hot water to multi-family buildings making the heat distribution costs low in dense urban areas with concentrated heat demands. Additionally, given the fact that DH reduces emissions (compared to individual boiler installations), the positive effects on urban air 
A New Simulation Model for Heating Production Plans: A Case Study on Romanian District Heating Systems

quality are obvious (Caserini, et al., 2010).The benefits of DH applications are also show in industries where they have replaced other types of energy in production processes (Difs, et al., 2009).

For many years, DH was the most important system use in post-communist states of Eastern and Central Europe (ECE) to centralize heat supply, serving buildings and industrial production processes. Extensive district heating systems appeared in European cities such as Warsaw, Hamburg, Helsinki, Berlin, Stockholm, Copenhagen, Paris, Prague, Sofia, and Bucharest. The main feature of these DH systems is related to the manner in which they were designed, around the time period before and immediately after World War II; they have not changed much since.

In the communist period, district heating systems were able to provide a universally-accessible energy service, which supported the extensive development of a centrally-planned economy. The post-communist transition was marked by the rise of technical, economic, regulatory, and environmental problems in the production and distribution of thermal energy which required the reform of initiatives to manage this sector.

This study focuses on Romania, where, between 2009 and 2014, the heat production capacity decreased from 684 in 2009 to 601 in 2014, representing a reduction in the installed capacity from 6.107 to 5.242 MW (Government of Romania, 2015).

Like other ECE states, Romania has a DH network that was designed on a large scale in order to deliver cheap energy to individual and industrial consumers. This involved the formation of centralized district-heating systems (CDHS). Unfortunately, most of these systems are technically and economically in deplorable conditions, and consequently system failures of varying duration are frequent in the cold season as well as energy wastage caused by poorly-insulated transport and distribution pipelines. Therefore, since the 1990s, a number of consumers have chosen to disconnect and adopt other individual heating solutions. It is known that large and centralized systems cannot assure district heating system efficiency, which is often as low as 50 percent due to production (up to $35 \%$ ) or distribution (up to 30\%) losses (Martinot, 1997). Beyond this, the thermal insulation of apartments to secure heat supplies has led to reduced heat energy consumption, and subsequently, a number of DH companies have gone into insolvency or bankruptcy (Governement of Romania , 2016).

Up until 2003, heating production was centrally regulated and owned by the state within a single public company, S.C. Termoelectrica S.A. After 2003, Termoelectrica S.A divided into multiple smaller state-owned companies, while the heat-delivery services were decentralized into Local Administrative Units (LAU). Therefore, one of the main characteristics of the DH system in Bucharest is 
Ioan Radu, Ion Smeureanu, Minodora Ursăcescu, Cleopatra Șendroiu, Mihai Demeter, Cristian Anton

that the DH service is not integrated; rather, the producer is owned by the state, and the distribution operator is owned by the local government.

In the years of post-communist transition, the decline of the DH sector became a reality. The World Energy Council emphasized serious structural difficulties for ECE states including increased energy losses in the generation, transportation, and distribution of heat as well as outdated equipment, over-sized network coverage, and irregular peak service. Moreover, many problems related to tariff distortions in favor of gas and electricity, payment arrears, the lack of metering, maintenance, and investment capital have been identified (World Energy Council (WEC), 2004). Therefore, a great number of Romanian industrial enterprises abandoned the centralized district heating system and developed their own power producing facilities (i.e., decentralized district heating systems).

Many changes also took place in the housing sector. In the 1990s, centralized district heating systems (CDHSs) represented the only manner of heating for 315 settlements in Romania; however, there were only 62 left in 2015, which covered the heating needs of only $20 \%$ of the stable population of the country (Government of Romania, 2015). In this context, CDHS heat consumption only accounted for $14.5 \%$ of the total demand in 2015 . The forecast for 2020 suggests that the district heating system will cover only $11.4 \%$ of the demand, rising to $16.3 \%$ by 2030 as a result of the energy efficiency measures in buildings and DH networks undertaken by Local Administrative Units (Government of Romania, 2015).

The housing sector is facing certain weaknesses in terms of infrastructural, technical, social, and institutional dimensions. For instance, households connected to the DH system of Bucharest are dealing with problems such as antiquated district heating systems with poorly controlled distribution systems and high losses, a lack of adequate metering to connect apartment buildings to the $\mathrm{DH}$ network, obsolete equipment, and over-sized network coverage. It is estimated that nearly $25 \%$ of the heat energy produced in Romania is lost before reaching consumers, these losses being three time higher than those reported in other European countries (Government of Romania, 2015). This is happening because the district heating supply and distribution pipes are old, poorly insulated, and in poor technical condition. According to (Government of Romania, 2015), only $20 \%$ of the transport network and $31 \%$ of the distribution network had been improved in the last 30 years. As a result of this inefficiency and different pricing policies, the cost per GJ in Romania is 20\% higher than in Finland (PWC (Price Waterhouse Coopers), 2011). On average, Romanian district heating prices in 2013 were 17.3 Euros per GJ (Werner, 2016).

The current decline of district heating networks in the housing sector continues to be a major problem, which requires both restructuring and reorganization. According to (PWC (Price Waterhouse Coopers), 2011), the centralized district heating system in Romania requires an investment of 5 billion 
A New Simulation Model for Heating Production Plans: A Case Study on Romanian District Heating Systems

Euros over the next 10 years, to improve its efficiency, reduce its losses, and align with European environmental standards.

All of these problems have led to negative reactions from the population, as well as a rising disconnection rate from the CDHS. Therefore, DH companies have been forced to impose higher charges on their remaining customers, thus creating a vicious institutional trap (Poputoaia \& Bouzarovski, 2010).

One of the most important issues related to the DH sector is having energyefficiency investments. This remains a challenge for both national and European legislation under the circumstances of reducing consumption by streamlining and diversifying energy sources.

There are many solutions that aim to improve the energy efficiency of DH systems (e.g., improving the DH supply and distribution systems, assuring longterm maintenance, and developing consumption-based metering and billing systems). In order to meet the conditions of energy efficiency in the housing sector (i.e., multi-family residential buildings), a heat energy production plan must be developed. This will involve improving the efficiency of the DH networks in the housing sector by determining the optimal quantity of heat that should be delivered to the population during the cold season.

It should be noted that, in Romania, DH system inefficiency and the lack of investments in combined heat and power (CHP) plants has led to increased natural gas consumption for domestic heating. According to (Werner, 2017), the proportion of heat supply from fossil fuels is still very high, both in the European Union (70\%) and in the world as a whole (90\%), as fossil fuels still represent the main energy supply group. Therefore, determining the optimal quantity of heat energy that must be produced on the DH system level is necessary.

In line with these statements, the purpose of this study is to develop a heat energy production plan by means of a dedicated simulation model that is applicable to the housing sector. The use of simulation models can provide important support in assessing the performance indicators that DH companies must achieve. They can also be useful tools for minimizing the influences of random factors that might impact the relationships between the district heat service and the final consumers (e.g., an unexpected decrease in the ambient temperature besides that which is forecast, and unexpected events in heat distribution that require additional heat production).

In order to determine the optimal quantities of heat energy that should be produced, a model that includes two optimization methods is proposed. First, a linear optimization method is used to optimize different production plans so that they can achieve different economic criteria. Second, all previously obtained production plans are gathered and an algorithm derived from fuzzy theory is used to determine the optimal decision, considering a set of technical, economic, and environmental criteria. 
Ioan Radu, Ion Smeureanu, Minodora Ursăcescu, Cleopatra Șendroiu, Mihai Demeter, Cristian Anton

\section{Materials and Methods}

The proposed model responds to the acute needs of the operator of the district heating system to optimize the level of heat produced to meet demands while also satisfying an optimum economic level. Thus, the proposed model takes $m$ thermal power plants (with $m$ being a natural number) which have to produce heat in a time horizon of $n$ months (with $n$ being a natural number) into account. Depending on certain technical restrictions, such as specific consumption, the total capacity produced by each power plant, the amount of gas to be purchased, and certain constraints on the minimum amount to be produced by each power plant, the model optimizes the quantity produced by each plant in each month in order to meet an economic optimum level.

To formalize the problem and derive the economic and mathematical models, we introduce the following notations:

1) $\mathrm{Q}^{\mathrm{P}}=\left(\begin{array}{ccccccc}q_{11}^{p} & q_{12}^{p} & q_{13}^{p} & q_{14}^{p} p & q_{15}^{p} & --- & q_{1 n}^{p} \\ q_{21}^{p} & q_{22}^{p} & q_{23}^{p} & q_{24}^{p} & q_{25}^{p} & --- & q_{2 n}^{p} \\ -\frac{-}{p}- & -\frac{-}{p}- & -\frac{-}{p}- & -\frac{-}{p}- & -\frac{-}{p}- & -- & -\frac{-}{p}- \\ q_{m 1}^{p} & q_{m 2}^{p} & q_{m 3}^{p} & q_{m 4}^{p} & q_{m 5}^{p} & --- & q_{m n}^{p}\end{array}\right)$ is the matrix of planned heat quantities to be manufactured by power plant $\mathrm{m}$ for the month $n$.

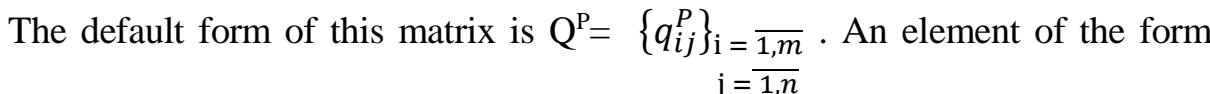
$\sum_{l=1}^{n}\left(\sum_{k=1}^{m} q_{k l}^{P}\right)$ represents the total planned heat quantity at $m$ thermal power plants each month.

2) $\mathrm{Q}^{\mathrm{i}}=\left(\begin{array}{cccc}q_{11}^{i} & q_{12}^{i} & --- & q_{1 n}^{i} \\ q_{21}^{i} & q_{22}^{i} & --- & q_{2 n}^{i} \\ --- & ---- & -- & --- \\ q_{m 1}^{i} & q_{m 2}^{i} & --- & q_{m n}^{i}\end{array}\right)$ is the production capacity matrix in relation to the quantity of gas scheduled to be purchased for each of the $m$ thermal power plants on the basis of previous statistical data for each month.

The default form of this matrix is $\mathrm{Qi}=\left\{q_{k l}^{i}\right\}_{\mathrm{k}=\overline{1, m}}$.

An element of form $\mathrm{Q}^{\mathrm{i}}$ is $q_{k l}^{i}$, where $\mathrm{k}=\frac{\mathrm{l}=\overline{1, n}}{1, m}$ is the number of thermal power plants and $1=\overline{1, n}$ is the number of months. An element of form $\sum_{l=1}^{n}\left(\sum_{k=1}^{m} q_{k l}^{i}\right)$ represents the total capacity installed for each thermal power plant for each month. 
A New Simulation Model for Heating Production Plans: A Case Study on Romanian District Heating Systems

3) $\mathrm{Q}^{\mathrm{g}}=\left(\begin{array}{cccc}q_{11}^{g} & q_{12}^{g} & --- & q_{1 n}^{g} \\ q_{21}^{g} & q_{22}^{g} & --- & q_{2 n}^{g} \\ -\frac{-}{g} & -\frac{-}{-g} & -- & -\frac{-}{g}- \\ q_{m 1}^{g} & q_{m 2}^{g} & --- & q_{m n}^{g}\end{array}\right)$ is the matrix of natural gas quantity available for the production of heat in each thermal power plant in each month.

An element of form $\mathrm{Q}^{\mathrm{g}}$ is $\mathrm{q}^{\mathrm{g}} \mathrm{kl}$, where $\mathrm{k}=\overline{1, m}$ and $\mathrm{l}=\overline{1, n}$. The default form of this matrix is $\mathrm{Q}^{\mathrm{g}}=\left\{q_{k l}^{g}\right\}_{\mathrm{k}=\overline{1, m}}$. An element of the form $\sum_{l=1}^{n}\left(\sum_{k=1}^{m} q_{k l}^{P}\right)$ represents $1=\overline{1, n}$

the total quantity of natural gas available at $m$ stations for each month.

The elements of all the above matrices are expressed in Mwh, and the relationship $1 \mathrm{Gcal}=1163 \mathrm{Mwh}$ holds.

4) $C S=\left(\begin{array}{cccc}C S_{11} & C S_{12} & --- & C S_{1 n} \\ C S_{21} & C S_{22} & --- & C S_{2 n} \\ --- & --- & --- & --- \\ C S_{m 1} & C S_{m 2} & --- & C S_{m n}\end{array}\right)$ is the matrix of specific gas consumption for the production of $1 \mathrm{Gcal}$, with its elements being expressed in MGW/Gcal.

5) $\mathrm{ET}(\mathrm{n})=\left\{E T_{1}, E T_{2}, E T_{3}, E T_{4}, E T_{5}, \ldots E T n\right\}$ is the the total heat quantity vector, produced by $m$ thermal power plants in each month $(n)$.

6) $\mathrm{F}(\mathrm{ET})=\sum_{i=1}^{n} E T_{i} * C_{i}$ is the objective function (or "optimization function"). Any element $\left(C_{i}\right)$ represents the unit value of the performance indicator taken into account to optimize the F(ET) function. In other words, the quantity of thermal energy produced by $m$ thermal power plants, for $n$ months in order to achieve the optimal level of the objective function.

With this notation, the explicit form of the model is as follows:

Determine the optimum value of $\mathrm{F}(\mathrm{ET})=\sum_{i=1}^{n} E T_{i} * C_{i}$, under the following restrictions:

1. $\left\{\begin{array}{l}C S_{11} * E T_{11}+C S_{12} * E T_{12}+C S_{13} * E T_{13}+C S_{14} * E T_{14}+\ldots+C S_{1 n} * E T_{1 n} \leq \sum_{K=1}^{m} q_{k 1}^{g} \\ C S_{21} * E T_{21}+C S_{22} * E T_{22}+C S_{23} * E T_{23}+C S_{24} * E T_{24}+\cdots+C S_{2 n} * E T_{2 n} \leq \sum_{K=1}^{m} q_{k 2}^{g} \\ -------------------------------- \\ C S_{m 1} * E T_{m 1}+C S_{m 2} * E T_{m 2}+C S_{m 3} * E T_{m 3}+C S_{m 4} * E T_{m 4}+C S_{m n} * E T_{m n} \leq \sum_{k=1}^{m} q_{k n}^{g}\end{array}\right.$
2. $\left\{\begin{array}{l}\sum_{k=1}^{m} q_{k 1}^{p}+\Delta 1 \leq E T 1 \leq \sum_{K=1}^{m} q_{k 1}^{i}+\Delta 1 \\ ----------- \\ \sum_{k=1}^{m} q_{k n}^{P}+\Delta \mathrm{n} \leq E T n \leq \sum_{K=1}^{m} q_{k n}^{i}+\Delta \mathrm{n}\end{array}\right.$

An element that must be taken into account is the requirement that all plants in the system must meet a minimum monthly thermal output, produced either to 
Ioan Radu, Ion Smeureanu, Minodora Ursăcescu, Cleopatra Șendroiu, Mihai Demeter, Cristian Anton

ensure the heat of a number of consumers connected to the centralized system or for other technical-economic reasons.

Therefore, the following model is complemented by a system of restrictive conditions that satisfies the requirement that each boiler has, in the case of any optimization, a minimum or maximum amount of thermal agent that it can produce:

3. $\left\{\begin{array}{c}\mathrm{Q}_{\min 11} \leq C S_{11} * E T_{11} \leq \mathrm{Q}_{\max 11} \mathrm{Q}_{\min 12} \leq C S_{12} * E T_{12} \leq \mathrm{Q}_{\max 12} \cdots \mathrm{Q}_{\min 1 n} \leq C S_{12} * E T_{1 n} \leq \mathrm{Q}_{\max 1 n} \\ \mathrm{Q}_{\min 21} \leq C S_{21} * E T_{21} \leq \mathrm{Q}_{\max 21} \mathrm{Q}_{\min 22} \leq C S_{22} * E T_{22} \leq \mathrm{Q}_{\max 22} \ldots \mathrm{Q}_{\min 2 n} \leq C S_{22} * E T_{2 n} \leq \mathrm{Q}_{\max 2 n} \\ ---------------------------------- \\ \mathrm{Q}_{\operatorname{minm} 1} \leq C S_{m 1} * E T_{m 1} \leq \mathrm{Q}_{\operatorname{maxm} 1} \mathrm{Q}_{\operatorname{minm} 2} \leq C S_{\mathrm{m} 2} * E T_{\mathrm{m} 2} \leq \mathrm{Q}_{\operatorname{maxm} 2} \cdots \mathrm{Q}_{\min m n} \leq C S_{m n} * E T_{m n} \leq \mathrm{Q}_{\max m n}\end{array}\right\}$

where $\mathrm{Qmin}_{\mathrm{mn}}$ is the minimum quantity to be produced by powerplant $m$ in month $n$ to meet a local heating agent requirement, and $\operatorname{Qmax}_{\mathrm{mn}}$ is the maximum quantity that can be produced by powerplant $m$ in month $n$ within the production capacity limits.

In the realization of the model (for the third restriction system), variable $\Delta$, a correction factor for the planned monthly quantity at the power plant level as well as the quantity of natural gas planned to be purchased, was taken into account. This factor allows the decision maker to parametrize the model for months in which he wants to produce a higher or lower amount of thermal energy to satisfy a certain optimal condition (economic, social, or technical). The real reasons that the decision maker would decide to use this correction factor for the initial situation are to determine the specific consumption with lower output of some plants in a given month, following the decision to use more gas in a particular month, the need to satisfy a peak in the monthly load, the anticipation of some meteorological phenomena with extremely low temperatures in a given month, or any other specific simulation that the decider wants to achieve.

The sum of ET1, ET2, ET3, ..., ETn represents the total amount of thermal energy to be produced in each plant for each month, provided that the planned thermal energy required to be produced is met (third restriction system), the maximum amount of natural gas available condition is respected (second restriction system), and also the minimum requirement of the heating agent to be produced by each plant for each month so as to achieve an optimal economic situation is met (first condition.)

Following the satisfaction of optimum condition (1), a number of programs for producing the quantity of thermal energy results, equal to the number of optimal conditions, are carried out.

$\mathrm{PPET}=\left\{\mathrm{ET}^{i}\right\}_{\mathrm{i}=\overline{1, p}}$ denotes the set of these programs, where $p$ is the number of optimal conditions. 
A New Simulation Model for Heating Production Plans: A Case Study on Romanian District Heating Systems

Next, the most favorable thermal energy production program needs to be identified. For this, from a decisional point of view, we find ourselves in the case of a multi-criteria decision under certainty for the following reasons:

a) The production programs, as a multitude of possible decisions (PPET), represent a finite set (discrete); and

b) the set of optimal criteria (denoted by OPT) is also a finite set (discrete).

Thus, the number of production programs, within a finite number of programs, that best meet (at the same time) a finite number of optimal conditions can be determined. For this, an algorithm derived from fuzzy theory is used.

We, therefore, propose to identify which thermal energy production program, out of the ones previously determined, is most favorable to be produced from the point of view of thermal power station management.

The following notations represent the initial assumptions for using the algorithm derived from fuzzy theory:

a. $\mathrm{C}=\left\{\mathrm{CEC}_{J}\right\}_{j=\overline{1, m}}$ is the set of criteria used to identify the optimal program. The number of criteria is at least equal to the number of optimal conditions.

b. $\mathrm{K}=\left\{\mathrm{k}_{j}\right\}_{j=1, m}$ is the set of important coefficients of each criterion of the optimal production program for all $\mathrm{j}=\overline{1, m}, \mathrm{k}_{\mathrm{j}} \in[2,6]$.

c. $\mathrm{CA}=\left\{\mathrm{CA}_{\mathrm{ij}}\right\}_{\mathrm{i}=\overline{1, p}}$ is the set of absolute consequences of each possible $\mathrm{j}=\overline{1, m}$

program for producing thermal energy, according to each criterion.

The elements of PPET are referred to as "possible decisions" (or "possible alternative decisions"). The values associated with the elements of set $\mathrm{K}$ must follow the following rule: If criterion $\mathrm{Cl}$ is more important than criterion $\mathrm{Ct}$ (with $1, \mathrm{t} \in[1, \mathrm{~m}])$, then the coefficient of importance $K l$ will have a value closer to 6 than the coefficient of importance $K t$.

Application of the fuzzy algorithm can be exemplified by starting from the explicit form of the CA (absolute consequences) matrix, with the following form:

$$
\mathrm{CA}=\left(\begin{array}{cccc}
C A_{11} & C A_{12} & --- & C A_{1 m} \\
C A_{21} & C A_{22} & --- & C A_{2 m} \\
--- & --- & --- & --- \\
C A_{p 1} & C A_{p 2} & --- & C A_{p m}
\end{array}\right), \text { where the natural number } p \text { denotes }
$$

the number of possible heat production programs, and $m$ is the number of criteria taken into account to determine the optimal program from the set of possible programs. 
Ioan Radu, Ion Smeureanu, Minodora Ursăcescu, Cleopatra Șendroiu, Mihai Demeter, Cristian Anton

To ensure the accuracy of the calculation, the elements of the CA matrix are expressed in relative values, resulting in the final matrix, $\mathrm{CR}$, of the relative consequences:

$$
\mathrm{CR}=\left(\begin{array}{cccc}
C R_{11} & C R_{12} & --- & C R_{1 m} \\
C R_{21} & C R_{22} & --- & C R_{2 m} \\
--- & --- & --- & --- \\
C R_{p 1} & C R_{p 2} & --- & C R_{p m}
\end{array}\right), \text { where any element } C R_{i j}=\frac{C A_{i j}}{\sum_{i=1}^{p} C A_{i j}},
$$

forall $\mathrm{j}=\overline{1, m}$.

The CR matrix of each possible heat production program allows the definition of the "Z matrix":

$\mathrm{j}=\overline{1, m}$.

$$
\mathrm{Z}=\left(\begin{array}{cccc}
z_{11} & z_{12} & --- & z_{1 m} \\
z_{21} & z_{22} & --- & z_{2 m} \\
--- & --- & --- & --- \\
z_{p 1} & z_{p 2} & --- & z_{p m}
\end{array}\right) \text {, where } \mathrm{Z}_{\mathrm{ij}}=\frac{\left|c R_{i j}-C_{j}^{x}\right|}{C_{j}^{x}}, \mathrm{i}=\overline{1, p} \text {, and }
$$

The element $C_{j}^{x}$ represents the most favorable relative consequence. This is determined by the relationship

$$
C_{j}^{x}= \begin{cases}\min _{i=\overline{1, p}}\left\{C R_{i j}\right\} & , \text { if the criterion } C R_{i j} \text { is minimal, for all } j=\overline{1, m} \\ \max _{i=\overline{1, p}}\left\{C R_{i j}\right\} & , \text { if the criterion } C R_{i j} \text { is maximal, for all } j=\overline{1, m}\end{cases}
$$

The $\mathrm{Z}$ matrix aids in generating the characteristic functions matrix $\mathrm{FC}$ $=\left\{\mathrm{FC}_{\mathrm{ij}}\right\}_{\mathrm{i}=\overline{1, P}}$, with the following form:

$$
\mathrm{J}=\overline{1, m}
$$

$$
\mathrm{FC}=\left(\begin{array}{cccc}
F C_{11} & F C_{12} & --- & F C_{1 m} \\
F C_{21} & F C_{22} & --- & F C_{2 m} \\
--- & --- & --- & --- \\
F C_{p 1} & F C_{p 2} & --- & F C_{p m}
\end{array}\right), \text { where any element } \mathrm{FC}_{\mathrm{ij}}=C^{-K_{j} Z_{i j}},
$$

for all $\mathrm{i}=\overline{1, p}$ andall $\mathrm{j}=\overline{1, m}$.

The FC matrix is subject to the following management methods for determining the optimal heat production program:

a) The pessimistic method (Abraham Wald)

The optimal program is the one that ensures maximum benefits when the minimum characteristic functions are considered from each of the possible 
A New Simulation Model for Heating Production Plans: A Case Study on Romanian District Heating Systems

alternative decisions. Mathematically, the optimal program is determined by the following formula:

$\mathrm{ET}($ optimal $)=\max _{\mathrm{i}=\overline{1, p}}\left\{\min _{\mathrm{j}=\overline{1, m}} F C_{i j}\right\}$., where ET is defined as one of the optimal thermal energy production plans obtained above.

b) The proportionality method (Bayes-Laplace)

This method assumes that each state of objective conditions has the same probability of occurrence and that the optimal program is the one that corresponds to a maximum value of the arithmetic mean of the characteristic functions. Mathematically, this condition is expressed as

$\mathrm{ET}($ optimal $)=\max _{\mathrm{i}=1, p}\left\{\frac{1}{m} \sum_{j=1}^{m} F C_{i j}\right\}$, where the optimal program results $\mathrm{ET}^{\mathrm{i}}$.

c) The optimality method (Leonid Hurwicz)

This is derived from the pessimistic and optimistic methods with the inclusion of a optimal coefficient $\alpha$, such that $\alpha \in(0,1)$. The optimum program is determined by the relationship

$$
\begin{aligned}
& \text { ET(optimal })=\max \left[\alpha A_{i}+(1-\alpha) a_{i}\right], \text { where } \\
& \mathrm{a}_{\mathrm{i}}=\min _{\mathrm{j}=\overline{1, m}}\left\{F C_{i j}\right\}, \mathrm{i}=\overline{1, p} \text {, and } \\
& \mathrm{A}_{\mathrm{i}}=\max _{\mathrm{j}=\overline{1, m} .}\left\{F C_{i j}\right\}, \mathrm{i}=\overline{1, p} .
\end{aligned}
$$

The optimal thermal energy production program will be the one that most often meets the specific conditions of the three methods outlined above.

It is noticeable that the determination of the optimal program by fuzzy techniques is influenced by the importance given by the decision maker to each of the optimal criteria, which leads to identification of the possible programs of thermal energy production.

We believe that this is an advantage as it gives the decision maker the opportunity to set the managerial situation and to orient the final decision according to the economic, social, environmental, and so on, priorities, which must be taken into account when planning the quantities of heat.

\section{Results}

Model application in Bucharest 
Ioan Radu, Ion Smeureanu, Minodora Ursăcescu, Cleopatra Șendroiu, Mihai Demeter, Cristian Anton

The management situation was simulated with eight thermal power plants which produce heat in Bucharest between October and March in order to ensure the thermal comfort of the inhabitants of several city districts. In this particular case, each power plant must satisfy a number of customers directly connected to it. Depending on the monthly efficiency of each plant, the amount of additional heat that can be produced will be introduced into the thermal energy transport ring in Bucharest. The parameters considered, according to the mathematical expressions above, were

- The planned heat quantity to be distributed by all eight power plants each month, based on statistical data from the last 5 years;

- The total quantity of gas to be procured for each month, also determined on the basis of statistical data;

- The minimum amount of heat to be produced by each boiler to satisfy the customers connected directly to the power plant;

- The amount of heat that can be produced by each boiler in each month; and

- The specific monthly consumption of each plant.

Using optimal condition (1) and restriction systems (2), (3), and (4), two scenarios were simulated, and two objective functions were optimized:

a. In the first scenario, the optimized objective function was the maximization of revenue and 78,680 Mwh was produced by thermal agents with each of the power plants producing a maximum amount of heat in each given month but priority being given to the more advantageous power stations.

b. In the second scenario, the objective cost minimization function was optimized, and 54,934 Mwh was produced by the thermal agent. Like the first scenario, each plant was considered to produce a minimum amount of heat in each given month, but priority was given to power plants with better specific consumption.

After obtaining the two production programs, they were compared using the algorithm derived from fuzzy theory, starting from the selection criteria presented in Table 1.

Table 1. Value of criteria associated with each production program

\begin{tabular}{|l|l|l|l|l|}
\hline Production programs & $\begin{array}{l}\text { Total } \\
\text { revenue (lei) } \\
(\mathrm{C} 1)\end{array}$ & $\begin{array}{l}\text { Total cost (lei) } \\
(\mathrm{C} 2)\end{array}$ & $\begin{array}{l}\text { Amount of gas to } \\
\text { be contracted } \\
(\mathrm{Mwh})(\mathrm{C} 3)\end{array}$ & $\begin{array}{l}\mathrm{CO}_{2} \\
\text { Emissions } \\
\text { (tons) }(\mathrm{C} 4)\end{array}$ \\
\hline $\begin{array}{l}\text { ET1 } \\
\text { (Production plan that } \\
\text { maximizes revenue) }\end{array}$ & $25,665,275$ & $21,139,611$ & 78,700 & $15,939.07$ \\
\hline $\begin{array}{l}\text { ET2 } \\
\text { (Production plan that }\end{array}$ & $16,134,262$ & $13,289,242$ & 54,934 & $11,125.83$ \\
\hline
\end{tabular}


A New Simulation Model for Heating Production Plans: A Case Study on Romanian District Heating Systems

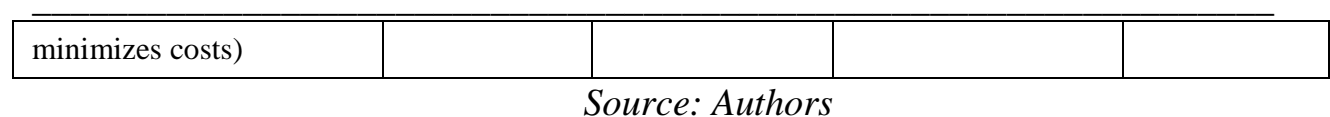

For each scenario, the same unit values were taken into account, as follows: unit revenue $=431 \mathrm{lei} / \mathrm{Mwh}$, unit cost $=300 \mathrm{lei} / \mathrm{Mwh}$, and $\mathrm{CO}_{2} / \mathrm{Mwh}=0.203$ tons/Mwh.

The level of importance associated with each criterion is shown in Table 2.

Table 2. The level of importance associated with each criterion considered

\begin{tabular}{|c|c|c|c|}
\hline Total Revenue (K1) & Total Cost (K2) & $\begin{array}{l}\text { Amount of gas to be } \\
\text { contracted (K3) }\end{array}$ & $\mathrm{CO}_{2}$ Emissions (K4) \\
\hline 5.2 & 5.8 & 4.6 & 5.9 \\
\hline
\end{tabular}

Source: Authors

The level of importance associated with each criterion is the choice of the decision-maker as an expert. There are no predefined values, and value may vary from one simulation to another, depending on the requirements taken into account at the level of the thermal power supply service at the time.

Following the application of the three management methods to determine the optimal thermal energy production program, we obtained the following:

Table 3. Pessimistic method (Abraham Wald)

\begin{tabular}{|l|l|l|l|l|l|l|}
\hline $\begin{array}{l}\text { Production } \\
\text { programs }\end{array}$ & $\begin{array}{l}\text { Total } \\
\text { Revenue } \\
\text { (maximum } \\
\text { value) C1 }\end{array}$ & $\begin{array}{l}\text { Total Cost } \\
\mathrm{C} 2\end{array}$ & $\begin{array}{l}\text { Amount of } \\
\text { gas to be } \\
\text { contracted } \\
\text { (minimum } \\
\text { value) C3 }\end{array}$ & $\begin{array}{l}\mathrm{CO}_{2} \\
\text { Emissions } \\
\text { (minimum } \\
\text { value) C4 }\end{array}$ & $\begin{array}{l}\text { Minimum } \\
\text { of C for } \\
\text { each ET }\end{array}$ & $\begin{array}{l}\text { Best } \\
\text { option }\end{array}$ \\
\hline $\begin{array}{l}\text { ET }^{1} \\
(\text { Maximize } \\
\text { revenue) }\end{array}$ & 1 & 0.16 & 0.13 & 0.07 & 0.07 & \\
\hline $\begin{array}{l}\text { ET } \\
(\text { Minimize } \\
\text { cost })\end{array}$ & 0.08 & 1.00 & 1 & 1 & 0.08 & 0,08 \\
\hline
\end{tabular}

Source: Authors

As can be observed from Table 3, using the pessimistic method, the ET2 production program was carried out at the expense of the ET1 production program because the lowest identified value associated with a criterion was higher than compared to the other program. 
Ioan Radu, Ion Smeureanu, Minodora Ursăcescu, Cleopatra Șendroiu, Mihai Demeter, Cristian Anton

Table 4. Proportionality method (Bayes-Laplace)

\begin{tabular}{|l|l|l|l|l|l|l|}
\hline $\begin{array}{l}\text { Production } \\
\text { programs }\end{array}$ & $\begin{array}{l}\text { Total Revenue } \\
\text { (maximum } \\
\text { value) } \mathrm{C} 1\end{array}$ & $\begin{array}{l}\text { Total } \\
\mathrm{Cost} \\
\mathrm{C} 2\end{array}$ & $\begin{array}{l}\text { Amount of } \\
\text { gas to be } \\
\text { contracted } \\
\text { (minimum } \\
\text { value) } \mathrm{C} 3\end{array}$ & $\begin{array}{l}\mathrm{CO}_{2} \\
\text { Emissions } \\
\text { (minimum } \\
\text { value) } \mathrm{C} 4\end{array}$ & $\max \left\{\frac{1}{5} \sum_{j=1}^{5} F C_{i j}\right\}$ & $\begin{array}{l}\text { Best } \\
\text { option }\end{array}$ \\
\hline $\begin{array}{l}\mathrm{ET}^{1} \\
\text { (Maximize } \\
\text { revenue) }\end{array}$ & 1 & 0.16 & 0.13 & 0.07 & 0.34 & 0.77 \\
\hline $\begin{array}{l}\text { ET } \\
\text { (Minimize } \\
\text { cost })\end{array}$ & 0.08 & 1 & 1 & 1 & 0.77 & \\
\hline
\end{tabular}

Source: Authors

As can be observed from Table 4, using the proportionality method, the ET2 production program was carried out at the expense of the ET1 production program as the optimal option.

Table 5. Optimality method (Leonid Hurwicz)

\begin{tabular}{|l|l|l|l|l|l|l|}
\hline $\begin{array}{l}\text { Production } \\
\text { programs }\end{array}$ & $\begin{array}{l}\text { Total } \\
\text { Revenue } \\
\text { (maximum } \\
\text { value) C1 }\end{array}$ & $\begin{array}{l}\text { Total } \\
\text { Cost C2 }\end{array}$ & $\begin{array}{l}\text { Amount of } \\
\text { gas to be } \\
\text { contracted } \\
\text { (minimum } \\
\text { value) C3 }\end{array}$ & $\begin{array}{l}\mathrm{CO}_{2} \\
\text { Emissions } \\
\text { (minimum } \\
\text { value) C4 }\end{array}$ & $\begin{array}{l}\alpha \cdot \mathrm{Ai}^{*}+ \\
(1-\alpha) \text { ai }\end{array}$ & $\begin{array}{l}\text { Best } \\
\text { option }\end{array}$ \\
\hline $\begin{array}{l}\mathrm{ET}^{1} \\
(\text { Maximize } \\
\text { revenue) }\end{array}$ & 1 & 0.16 & 0.13 & 0.07 & 0.44 & 0.44 \\
\hline $\begin{array}{l}\text { ET } \\
(\text { Minimize } \\
\text { cost) }\end{array}$ & 0.08 & 1 & 1 & 1 & 0.44 & \\
\hline
\end{tabular}

Source: Authors

*Ai represents the highest identified value associated with a criterion for a specific ET.

*ai represents the lowest identified value associated with a criterion for a specific ET. 
A New Simulation Model for Heating Production Plans: A Case Study on Romanian District Heating Systems

For the application of the optimality method, we considered an alpha coefficient of 0.4, which implies a fairly equidistant approach between the optimistic and the pessimistic, but with a small inclination towards the pessimistic one. As an optimal option, the ET2 manufacturing program resulted, at the expense of the ET1 manufacturing program.

Following computer processing using the Excel for mathematical models presented above, the ET2 thermal energy production program was found to be more advantageous than the ET1 program. The optimal program, thus determined, considers the minimal production of a thermal agent, provided that a global requirement calculated on previous statistical data and the quantity of the local heating agent that has to be produced at each power plant to supply a number of consumers connected directly is met.

\section{Discussion}

The simulation performed in this study had both a structural dimension and a pragmatic one. These dimensions ensure the wide applicability of this simulation in centralized district heating systems. Its structural dimension results from the following features:

1) A large number of thermal power plants, producing thermal energy at the level of a territorial administrative unit, may be considered; and

2) Optimal conditions can be varied, enabling large-scale heat production programs to cover a wide spectrum of optimized performance indicators (economic, financial, social, and environmental). Obviously, depending on the nature of each optimization, the second, third, and fourth restriction systems will retain their shapes but will change their significance.

Regarding its pragmatic dimension, we appreciate that simulations are a crucial support system for decision-making, as they make it possible to identify the most favorable thermal energy production program at any given time. Decision makers have the possibility to perform multiple simulation scenarios by

1) Conducting modifications of the third system of restrictions (by means of the variable $\Delta$ ) when they consider that, during the period over which the simulation is made, factors that alter the initial data of the simulation can occur. As mentioned above, they can be generated by factors such as specific consumption with a lower output of plants in a particular month, the decision to use more gas in a given month, the need to meet a peak load, the anticipation of some meteorological phenomenon with particularly low temperatures in a given month, or any other factor that the decision-maker wants to take into account; and

2) Assigning different coefficients of importance to each criterion, according to which, the most favorable thermal energy production program is determined when applying the fuzzy algorithm. 
Ioan Radu, Ion Smeureanu, Minodora Ursăcescu, Cleopatra Șendroiu, Mihai Demeter, Cristian Anton

Through the two dimensions discussed above, the simulation of the process of determining an optimal thermal energy production program fulfills the conditions of a decision support system or an interactive decision-support system related to the operation of a district heating system.

\section{Conclusions}

The adaptation of an operator to competitive conditions as well as the correct positioning of the strategic approach to achieve economic performance and financial sustainability requires a pro-active approach to resource allocation and achievement of planned results. As the operators of district heating systems depend, to a large extent, on the financial resources of the local authority (through subsidies), the efficiency of their activity represents a significant factor in the optimization of public expenditure.

Therefore, this simulation has a strong predictive character in the direct management of the district heating system as well as in the construction of the local administrations budget. We consider that simulations can become an important part of an integrated district heating system through ensuring its managerial efficiency by influencing the functions of forecasting, organizing, and coordinating the functioning of the district heating system at the level of a territorial administrative unit.

In future research, we aim (starting from the production plan obtained in the simulation) to determine the optimal production cost that ensures a high level of economic performance for the local authority, operator, and consumer.

\section{REFERENCES}

[1]Caserini, S. et al.(2010),LCA of Domestic and Centralized Biomass

Combustion: The Case of Lombardy (Italy).Biomas Bioenerg, Volume 34, pp. 474-482;

[2] Chittum, A. \& Østergaard, P. A.(2014), How Danish Communal Heat Planning Empowers Municipalities and Benefits Individual Consumers.Energy policy, pp. 465-474;

[3] Colemnar-Santos, A., Rosales-Asensio, E. \& Borge Diez, D.( 2016),District

Heating Cogeneration in the EU-28: Current Situation, Potential and Proposed Energy Strategy for its Generalisation. Renewable and Sustainable Energy Reviews, pp. 621-639;

[4] Difs, K., Danestig, M. \& Trygg, L.(2009),Increased Use of District Heating in Industrial Processes - Impacts on Heat Load Duration.Appl Energ. Volume 76, pp. 2327-2334;

[5] EC (European Commision) (2012),Directive 2012/27/EU of the European

Parliament and of the Council of 25 October 2012 on Energy Efficiency, 
A New Simulation Model for Heating Production Plans: A Case Study on Romanian District Heating Systems

amending Directives 2009/125/EC and 2010/30/EU and repealing Directives 2004/8/EC and 2006/32/EC., s.l.: s.n;

[6] EC (European Commission) (2009),Directive 2009/28/EC of the European Parliament and of the Council of 23 April 2009 on the use of energy from renewable sources and amending and subsequently repealing Directives 2001/77/EC and 2003/30/EC., s.l.: s.n;

[7] Galindo Fernández, M., Roger-Lacan, C., Aumaitre, V. \& Gährs,U. U(2016),Efficient District Heating and Cooling Systems in the EU - Case Studies Analysis, Replicable Key Success Factors and Potential Policy Implications, s.1.: EUR $28418 \mathrm{EN}$;

[8] Gasparini et al.(2015),Mortality Risk Atributed to High and Low Ambient Temperature: A Multicountry Observational Study.Lancet, pp. 369-375;

[9] Governement of Romania (2016),Raport al sesiunii de lucru: Eficiență energetică, energie termică și cogenerare. Strategia Energetică a României 20162030, cu perspectiva anului 2050, s.l.: s.n;

[10] Government of Romania (2015),Raport privind evaluarea potentialului national de punere in aplicare a cogenerarii de inalta eficienta si a termoficarii si racirii centralizate eficiente, s.l.: s.n; [11] Leca, A. (2015),Romania Needs A Strategy for Thermal Energy. Management \& Marketing. Challenges for the Knowledge Society,10(1); [12] Martin, M. \& Thornley P,(2013), The Potential for Thermal Storage to Reduce the Overall Carbon Emissions from District Heating Systems; Tyndall Centre for Climate Change Research;

[13] Martinot, E. (1997),Investments to Improve the Energy Efficiency of Existing Residential Buildings in Countries of the Former Soviet Union, s.1.: World Bank Publications;

[14] Poputoaia, D. \& Bouzarovski, S. (2010), Regulating District Heating in Romania. Legislative challenges and energy efficiency barriers.. Energy policy, Volume 38, pp. 3820-3829;

[15] PWC (Price Waterhouse Coopers) (2011),Provocări și oportunități pentru sistemul de furnizare centralizată a energiei termice în România. București: $P W C$;

http://www.pwc.ro/en/publications/assets/assets_2011/Provocari_Oportunitati_En ergie_Term ica.pdf., s.l.: s.n;

[16] Werner, S. (2004),District Heating and Cooling. pp.841-8481; Encyclopedia of Energy;

[17] Werner, S. (2016),European District Heating Price Series, s.l.:

ENERGIFORSK;

[18] Werner, S. (2017),International Review of District Heating and Cooling. Energy, October, Volume 137, pp. 617-631; 
Ioan Radu, Ion Smeureanu, Minodora Ursăcescu, Cleopatra Șendroiu, Mihai Demeter, Cristian Anton

[19] World Energy Council (WEC) (2004),Regulating District Heating and Cogeneration in Central and Eastern Europe: A Report of the World Energy Council. WEC, London., s.l.: s.n. 